\title{
AN ASSESSMENT OF THE ASSIGNMENT METHOD IN ECONOMIC BASE ANALYSIS
}

\author{
Gordon F. Mulligan and Alexander C. Vias*
}

\begin{abstract}
Numerous techniques have been devised to make economic base analysis more cost-effective. The simplest of these, the assignment or assumption method, allocates the entire employment (income) of each industry to either the basic or nonbasic sector of the regional economy. Unfortunately, employment data have not been generally available in a form appropriate for evaluation of the assignment method. This paper combines a unique body of survey-generated employment data with OLS regression procedures in providing such an evaluation. Competing values of economic base multipliers, derived from the assignment method and the "correct" benchmark method, are estimated for various types of communities. These estimates, reflecting two rather different interpretations of the economic base logic, are shown to be remarkably similar in size, but not in composition. The study uses the Arizona Community Data Set, a data base covering 47 towns in the U.S. Southwest.
\end{abstract}

\section{INTRODUCTION}

Economic base analysis enjoys a long tradition as a cost-effective means for analyzing small regional economies. The approach has been widely used to model employment (income) impacts in communities, counties, and multi-county regions here in the U.S. (Mulligan and Gibson 1984; Richardson 1985; Malecki 1991). This paper uses the Arizona Community Data Set to estimate economic base multipliers in a representative sample of small U.S. communities. The research extends the work of Mulligan and Kim (1991), who demonstrated that multipliers vary with community specialization.

The main intention is to evaluate the assignment or assumption method in economic base analysis. This simple procedure has been frequently used to bifurcate regional employment into its basic (export-oriented) and nonbasic (locallyoriented) components. Here the practitioner essentially uses personal judgment to assign entire industries to either category. Agriculture, mining, manufacturing, and federal government are generally assigned to the basic category, while most service and trade activities are typically assigned to the nonbasic category. The remaining activities are variously assigned, partly depending upon local cir-

\footnotetext{
*Professor, Department of Geography and Regional Development, University of Arizona, and Ph.D. candidate, Department of Geography and Regional Development, University of Arizona, respectively. The authors thank two referees for their helpful comments. An earlier version of this paper was presented at the 35th Meeting of the Western Regional Science Association in Napa, February 1996.
} 
cumstances, and this assignment approach has been the source of much discussion in the literature.

The assignment approach has been used in numerous well-known studies (Braschler 1972; Weiss and Gooding 1968; Garnick 1970; Moody and Puffer 1970; Polzin 1973, 1977; Chalmers and Anderson 1977; McNulty 1977; Chalmers et al. 1978). This is somewhat surprising in light of the weak theoretical rationale for the approach. In all fairness, though, there exist numerous cases where practitioners have used survey data or averaging techniques to modify the simple binary assignments. However, as Isserman (1980) has so clearly indicated, when using the technique the practitioner is really hoping "... that the overestimates of exports when industries are assigned to export are balanced by the underestimates when industries are assigned entirely to local." Clearly, then, the findings of these studies must be approached with some skepticism simply because the assignment method, and not the correct survey-based method, was used to allocate regional employment (income) into its basic and nonbasic components. Moreover, upon adopting this shortcut method, most practitioners probably could not even gauge whether they were overpredicting or underpredicting the regional multiplier.

Unfortunately, the assignment technique has been the subject of few, if any, evaluations. ${ }^{1}$ The primary purpose of this paper is to provide such an evaluation, at least as the method can be applied to the 2-digit SIC employment data of the Arizona Community Data Set (ACDS). The next section of the paper provides background material regarding this valuable data base.

Section 3 of the paper summarizes four competing versions of the "correct" economic base model, as outlined by Mulligan and Kim (1991). For each version, OLS regression techniques are used to estimate marginal multipliers in the ACDS. Industry-level estimates of nonbasic employment are given for every industry in the economy, whether or not that industry is known to be primarily basic or nonbasic in orientation. Aggregation of these estimates leads to the multipliers, which are then adopted as benchmark values for subsequent analysis.

Section 4 then examines the four counterpart versions of the assignment economic base model. Since entire industries are assigned to either the basic or nonbasic category, the model is "incorrect" in its specification. OLS regression is used again to generate estimates of nonbasic employment at the level of individual industries. The paper examines alternative assignment scenarios (i.e., different combinations of assigned industries) and identifies that scenario, providing results closest to those of the "correct" model.

These assignment scenarios are evaluated on four separate criteria. First, if appropriate, a scenario is rated by its ability (adjusted $\mathbf{R}^{2}$ ) to estimate communitywide nonbasic employment, since that estimate is the critical determinant of the multiplier. Second, and most important, the assignment and benchmark multiplier 
estimates are directly compared to ascertain that scenario having the lowest estimation error. Economic base analysis should not only focus on the economywide estimate of nonbasic employment, which is used to estimate the size of the multiplier effect, but should also focus on the industry-level estimates of nonbasic employment, which shed light on the composition of the multiplier effect. Thus, a third criterion for evaluation is provided by the statistical properties of the various industry-level assignment regressions themselves. Fourth, and least important, the expected industrial composition of the impact is examined for different assignment scenarios and these are compared to the benchmark composition.

Section 5 then uses dummy variables to control stepwise regression estimates for a variety of community specializations. The approach follows that of Mulligan and Fik (1994), who provided multiplier estimates for five different functional types. Again, results from the assignment method are compared to appropriate benchmark results and the accuracy of the assignment method is evaluated.

\section{THE ARIZONA COMMUNITY DATA SET}

The analysis makes use of the ACDS, a data base comprised of 47 settlement-wide employment surveys that were undertaken in the U.S. Southwest during the 1970s and $1980 \mathrm{~s}^{2}$. These places, ranging in population size between 3,000 and 15,000 , were all fully surveyed in the field at the establishment level. Full-time, part-time, and seasonal employment, classified at the 4-digit SIC level, were transformed into full-time equivalent (FTE) form, and this in turn was split into its basic and nonbasic components according to the geographic sources of revenue disclosed by the establishment. SIC guidelines were then used to aggregate the data to the 2-digit level. Some adjustments were made for the commuting patterns of employees. However, these employment data were not weighted by the differential wage levels earned in different industries. Details regarding the survey methodology are available elsewhere (Gibson and Worden 1981; Mulligan and Gibson 1984).

Ten industries are used in generating all of the statistical estimates: Along with their associated acronyms, these industries are as follows: agriculture (AGRIC), mining (MINIG), construction (CONST), manufacturing (MANUF), transportation, communications, and public utilities (TCPUT), wholesale trade (WTRAD), retail trade (RTRAD), finance, insurance, and real estate (FIRES), services (SERVS), and public administration (PADMN).

In this paper three industries (AGRIC, MINIG, MANUF) are always assigned as basic, while four industries (CONST, RTRAD, FIRES, SERVS) are always assigned as nonbasic. Construction tends to be a basic activity in the boom 
towns and metropolitan satellites of the ACDS but is normally a nonbasic activity in other centers. The remaining three industries (TCPUT, WTRAD, PADMN) can be classified as either basic or nonbasic, depending upon the chosen assignment scenario. Based on all possible combinations of the ten ACDS industries, eight different assignment scenarios can be specified.

The ACDS also provides public transfer-payment data for each community during its survey year, recognizing the importance of these payments as additional sources of basic income. These monetary figures were transformed into an employee-equivalent form by applying community-specific payroll figures for appropriate survey years. Unfortunately, data for other types of nonemployment income were not available for the ACDS communities.

\section{THE BENCHMARK MODEL}

As shown in Mulligan and Kim (1991), four different methods can be used to estimate the "correct" economic base model. In each case, industry-level nonbasic employment is estimated before community-wide nonbasic employment is specified. Methods 1 and 3 adopt different measures of community-wide employment as the single explanatory variable, while methods 2 and 4 use public transfer payments as a second explanatory variable.

In method 1, by far the most popular interpretation of economic base analysis, nonbasic employment $\mathrm{E}_{\mathrm{Ni}}$ in the ith $(1 \leq \mathrm{i} \leq 10)$ industry is driven by community-wide basic employment $\mathrm{E}_{\mathrm{B}}$ :

$$
\mathrm{E}_{\mathrm{Ni}}=\alpha_{0 \mathrm{i}}+\alpha_{1 \mathrm{i}} \mathrm{E}_{\mathrm{B}}+\mathrm{e}
$$

where $e$ is the error term. Community-wide nonbasic employment $E_{N}$ is estimated as

$$
E_{N}=\alpha_{0}+\alpha_{1} E_{B}+e,
$$

where $\alpha_{1}$ indicates the propensity of community-wide basic employment to create nonbasic employment. Note that the estimates in equation (1) could also be summed over all industries in order to provide the same estimates given by equation (2). The estimate of the economic base multiplier is

$$
\mathbf{M}_{\alpha}=1+\alpha_{1}
$$


while the proportion of the impact shift $\Delta \mathrm{E}_{\mathrm{N}}$ allocated to the ith industry is

$$
b_{i}=\left(\alpha_{1 i} / \alpha_{1}\right) \times 100 \% \text {. }
$$

Method 2 introduces public transfer payments TR as a second explanatory variable. Nonbasic employment is estimated as

$$
\begin{aligned}
& E_{N i}=\alpha_{0 i}+\alpha_{1 i} E_{B}+\alpha_{2 i} T R+e \\
& E_{N}=\alpha_{0}+\alpha_{1} E_{B}+\alpha_{2} T R+e
\end{aligned}
$$

where the coefficient $\alpha_{2}$ indicates the propensity of public transfer payments to create nonbasic employment. Equations (3) and (4) also hold for method 2.

Theory suggests that transfer payments will not affect the nonbasic employment of each industry in the same way. Consequently, coefficients for TR were adopted only when the estimate $\alpha_{2 i}$ was significant at the 0.05 level. In these cases the estimate $\alpha_{1 \mathrm{i}}$ for basic employment was taken from equation (5); otherwise, the estimate was taken directly from equation (1).

The top half of Table 1 shows the various estimates $\alpha_{1 \mathrm{i}}$ for the two methods. In each case the employment estimate is significant at the 0.05 level. Note that these estimates are slightly different from those given in Mulligan and Kim (1991, Table 2), largely because AGMNG has now been divided into AGRIC and MINIG.

The estimate $\alpha_{1}$ is 0.6375 in equation (2) and 0.4409 in equation (6), thereby indicating that the multiplier estimate is considerably higher for method 1 $\left(M_{\alpha}=1.637\right)$ than for method $2\left(M_{\alpha}=1.441\right)$. As Mulligan and Kim (1991) have pointed out, any neglect of transfer payments means that practitioners will overpredict economic base multipliers.

Values for $b_{i}$, the proportion of the shift $\Delta \mathrm{E}_{\mathrm{N}}$ allocated to the ith industry, are not given due to space limitations. ${ }^{3}$ These data indicate, for example, that for 100 new nonbasic jobs created by an economic impact, between 26.87 (method 2) and 30.80 (method 1) of these jobs should appear in RTRAD, while between 30.84 (method 2) and 32.60 (method 1) of these jobs should appear in SERVS.

In method 3 nonbasic employment is assumed to be driven by communitywide total employment $\mathrm{E}_{\mathrm{T}}$, making the economic base model more consistent with the Keynesian approach (Hewings 1977). In order to avoid regressing nonbasic employment $\mathrm{E}_{\mathrm{Ni}}$ on itself the economic base model is first estimated as

$$
\mathrm{E}_{\mathrm{Ni}}=\alpha_{0 \mathrm{i}}+\alpha_{1 \mathrm{i}} \mathrm{E}_{\mathrm{T}^{*}}+\mathrm{e},
$$


TABLE 1

Employment Estimates for the Benchmark Model

\begin{tabular}{|c|c|c|c|c|c|c|}
\hline \multirow[b]{2}{*}{ Industry } & \multicolumn{3}{|c|}{ Method 1} & \multicolumn{3}{|c|}{ Method 2} \\
\hline & $\alpha_{1 i}$ & t-score & $\operatorname{adj} R^{2}$ & $\alpha_{1 i}$ & t-score & $\operatorname{adj} R^{2}$ \\
\hline$\overline{\text { AGRIC }}$ & 0.0068 & 2.33 & 0.09 & 0.0068 & 2.33 & 0.09 \\
\hline MINIG & 0.0048 & 3.59 & 0.21 & 0.0048 & 3.59 & 0.21 \\
\hline CONST & 0.0318 & 3.81 & 0.23 & 0.0318 & 3.81 & 0.27 \\
\hline MANUF & 0.0263 & 4.27 & 0.27 & 0.0263 & 4.27 & 0.27 \\
\hline TCPUT & 0.0399 & 2.52 & 0.10 & 0.0399 & 2.52 & 0.10 \\
\hline WTRAD & 0.0131 & 3.76 & 0.22 & 0.0082 & 2.12 & 0.30 \\
\hline RTRAD & 0.1963 & 6.88 & 0.50 & 0.1069 & 4.96 & 0.79 \\
\hline FIRES & 0.0409 & 6.75 & 0.49 & 0.0229 & 4.68 & 0.76 \\
\hline SERVS & 0.2078 & 7.48 & 0.54 & 0.1227 & 5.67 & 0.80 \\
\hline \multirow[t]{2}{*}{ PADMN } & 0.0697 & 7.90 & 0.57 & 0.0706 & 5.73 & 0.66 \\
\hline & \multicolumn{3}{|c|}{ Method 3} & \multicolumn{3}{|c|}{ Method 4} \\
\hline Industry & $\alpha_{1 i}\left(\beta_{1 i}\right)$ & t-score & $\operatorname{adj} R^{2}$ & $\alpha_{1 i}\left(\beta_{1 i}\right)$ & $\mathrm{t}$-score & $\operatorname{adj} \mathbf{R}^{2}$ \\
\hline AGRIC & $\begin{array}{c}0.0055 \\
(0.0055)\end{array}$ & 3.37 & 0.18 & $\begin{array}{c}0.0055 \\
(0.0055)\end{array}$ & 3.37 & 0.18 \\
\hline MINIG & $\begin{array}{c}0.0028 \\
(0.0028)\end{array}$ & 3.67 & 0.21 & $\begin{array}{c}0.0028 \\
(0.0028)\end{array}$ & 3.67 & 0.21 \\
\hline CONST & $\begin{array}{c}0.0225 \\
(0.0220)\end{array}$ & 4.86 & 0.33 & $\begin{array}{c}0.0225 \\
(0.0220)\end{array}$ & 4.86 & 0.33 \\
\hline MANUF & $\begin{array}{c}0.0176 \\
(0.0173)\end{array}$ & 5.14 & 0.36 & $\begin{array}{c}0.0176 \\
(0.0173)\end{array}$ & 5.14 & 0.36 \\
\hline TCPUT & $\begin{array}{c}0.0258 \\
(0.0252)\end{array}$ & 2.76 & 0.13 & $\begin{array}{c}0.0258 \\
(0.0252)\end{array}$ & 2.76 & 0.13 \\
\hline WTRAD & $\begin{array}{c}0.0098 \\
(0.0097)\end{array}$ & 5.37 & 0.38 & $\begin{array}{c}0.0098 \\
(0.0097)\end{array}$ & 5.37 & 0.38 \\
\hline RTRAD & $\begin{array}{c}0.1542 \\
(0.1336)\end{array}$ & 10.16 & 0.69 & $\begin{array}{c}0.0943 \\
(0.0862)\end{array}$ & 6.50 & 0.84 \\
\hline FIRES & $\begin{array}{c}0.0293 \\
(0.0285)\end{array}$ & 10.76 & 0.71 & $\begin{array}{c}0.0191 \\
(0.0187)\end{array}$ & 6.31 & 0.81 \\
\hline SERVS & $\begin{array}{c}0.1581 \\
(0.1365)\end{array}$ & 10.27 & 0.69 & $\begin{array}{c}0.1003 \\
(0.0912)\end{array}$ & 6.49 & 0.82 \\
\hline PADMN & $\begin{array}{c}0.0468 \\
(0.0447)\end{array}$ & 10.40 & 0.70 & $\begin{array}{c}0.0468 \\
(0.0447)\end{array}$ & 10.40 & 0.70 \\
\hline
\end{tabular}

Note: The estimates pertain to the employment coefficients of equations (1), (5), (7), and (12). Adjusted estimates per equations (8) and (13) are shown in parentheses. All employment estimates are significant at the 0.05 level. 
where $\mathrm{ET}^{*}=\mathrm{E}_{\mathrm{T}}-\mathrm{E}_{\mathrm{Ni}}$ is the residual total employment. Applying algebra, equation (7) can be restated as

$$
E_{N i}=\beta_{0 i}+\beta_{1 i} E_{T} \text {, }
$$

and, upon summation,

$$
E_{N}=\beta_{0}+\beta_{1} E_{T} \text {, }
$$

where the coefficient $\beta_{1}$ indicates the propensity for community-wide total employment to create nonbasic employment. Note that equation (9) is not estimated directly, but is generated by aggregating the estimates in equation (8). Now the estimate of the economic base multiplier is

$$
M_{\beta}=1 /\left(1-\beta_{1}\right)
$$

where the percentage allocation of the impact shift $\Delta \mathrm{E}_{\mathrm{N}}$ is

$$
b_{i}=\left(\beta_{1 i} / \beta_{1}\right) \times 100 \%
$$

Method 4 then includes public transfer payments TR as a second explanatory variable. Now nonbasic employment at the industry level is estimated as

$$
\mathrm{E}_{\mathrm{Ni}}=\alpha_{0 \mathrm{i}}+\alpha_{1 \mathrm{i}} \mathrm{E}_{\mathrm{T}^{*}}+\alpha_{2 \mathrm{i}} \mathrm{TR}+\mathrm{e}
$$

where, as before, only those estimates $\alpha_{2 i}$ significant at the 0.05 level are retained. The results can be easily transformed into

$$
E_{N i}=\beta_{0 i}+\beta_{1 i} E_{T}+\beta_{2 i} T R \text {, }
$$

indicating that community-wide nonbasic employment is

$$
E_{N}=\beta_{0}+\beta_{1} E_{T}+\beta_{2} T R \text {. }
$$

Equations (10) and (11) also hold for method 4.

The bottom half of Table 1 shows the various employment estimates $\alpha_{1 \mathrm{i}}$ of methods 3 and 4. Again, it is worthwhile to note that all of these estimates are significant at the 0.05 level. Note, too, that the adjusted $R^{2}$ values are higher for methods 3 and 4 than for methods 1 and 2, respectively, thereby indicating the superior predictions of the models using total employment, and not just basic 
employment, as an explanatory variable. The adjusted estimates $\beta_{1 \mathrm{i}}$ are also given in the appropriate places. The estimate $\beta_{1}$ is 0.4258 in equation (9) and 0.3233 in equation (14), indicating again the important role of transfer payments in affecting the level of nonbasic employment. The related multiplier estimates are $M_{\beta}=1.741$ and $\mathrm{M}_{\beta}=1.478$, respectively. Note that these two estimates of the multiplier are marginally higher than their counterparts stated earlier.

\section{THE ASSIGNMENT MODEL}

Under the assignment approach, the total employment of entire industries is designated as being either basic or nonbasic. As pointed out earlier, just how these industries are actually classified is a matter of some debate. Nevertheless, it is possible to identify an assignment method that is the direct counterpart to each benchmark method discussed above.

Recall that methods 1 and 2 use community-wide basic employment as the independent variable. Suppose that $j$ industries are assigned as nonbasic and that the remaining 10-j industries are assigned as basic. Then, for the purposes of this paper, the total employment in as few as $\mathrm{j}=4$ industries (CONST, RTRAD, FIRES, and SERVS), and in as many as $j=7$ industries (CONST, TCPUT, WTRAD, RTRAD, FIRES, SERVS, and PADMN), can be entirely assigned as nonbasic. In all there are eight different assignment scenarios.

Denote the total employment in the ith $(1 \leq i \leq j \leq 7)$ nonbasic industry as $\mathrm{E}(\mathrm{N})_{\mathrm{Ti}}$, total employment in all nonbasic industries as $\mathrm{E}(\mathrm{N})_{\mathrm{T}}$, and total employment in all basic industries as $\mathrm{E}(\mathrm{B})_{\mathrm{T}}$. Then the assignment counterparts to equations (1) through (6) are:

$$
\begin{aligned}
\mathrm{E}(\mathrm{N})_{\mathrm{Ti}} & =\gamma_{0 \mathrm{i}}+\gamma_{1 \mathrm{ii}} \mathrm{E}(\mathrm{B})_{\mathrm{T}}+\mathrm{e} \\
\mathrm{E}(\mathrm{N})_{\mathrm{T}} & =\gamma_{0}+\gamma_{1} \mathrm{E}(\mathrm{B})_{\mathrm{T}}+\mathrm{e} \\
\mathrm{M}_{\gamma} & =1+\gamma_{1} \\
\mathrm{~b}_{\mathrm{i}} & =\left(\gamma_{1 \mathrm{i}} / \gamma_{1}\right) \times 100 \% \\
\mathrm{E}(\mathrm{N})_{\mathrm{Ti}} & =\gamma_{0 \mathrm{i}}+\gamma_{1 \mathrm{i}} \mathrm{E}(\mathrm{B})_{\mathrm{T}}+\gamma_{2 \mathrm{i}} \mathrm{TR}+\mathrm{e} \\
\mathrm{E}(\mathrm{N})_{\mathrm{T}} & =\gamma_{0}+\gamma_{1} \mathrm{E}(\mathrm{B})_{\mathrm{T}}+\gamma_{2} \mathrm{TR}+\mathrm{e} .
\end{aligned}
$$


Obviously, the propensity $\gamma_{1}$ to create nonbasic employment, the size $\mathrm{M}_{\gamma}$ of the multiplier, and the composition $b_{i}$ of the impact will all depend upon the number $j$ of sectors that are chosen to be nonbasic.

First of all, note that equation (16), like its counterpart, equation (2), can be directly estimated. OLS regressions indicate that the highest adjusted $R^{2}(0.448)$ is found in the scenario having the greatest number (six) of basic industries (with $j=4$ nonbasic industries), while the lowest $R^{2}(0.200)$ is found in the scenario having the lowest number (three) of basic industries (with $j=7$ nonbasic industries). This confirmed the a priori expectation, since overall variation in nonbasic employment is smallest for the $j=4$ case and greatest for the $j=7$ case.

As shown in Table 2, when there are $\mathrm{j}=4$ nonbasic industries the employment coefficient in equation (16) is $\gamma_{1}=0.6411$ and, consequently, the estimate of the multiplier is $M_{\gamma}=1.641$; however, when there are $j=7$ nonbasic industries, the employment coefficient increases to $\gamma_{1}=0.6838$ and the multiplier estimate shifts to $M_{\gamma}=1.684$. The $j=4$ scenario is marginally superior on criterion two, generating a multiplier value remarkably close to the benchmark value of $M_{\alpha}=1.637$. This result could not be anticipated a priori.

Moreover, when the industry-specific estimates of $\gamma_{1 i}$ are examined in equation (15), per criterion three, the $j=4$ scenario again proves the best of the eight assignment scenarios. As the left-hand data in Table 2 indicate, in the $j=4$ case there is only one insignificant estimate of $\gamma_{1 i}$ (in CONST) but, when $j=7$, there are three insignificant estimates. Besides, the $t$-scores are much higher for CONST, RTRAD, FIRES, and SERVS in the $j=4$ scenario.

However, a conflicting perspective arises when the fourth criterion, the composition of the shift $\Delta \mathrm{E}\left(\mathrm{N}_{\mathrm{T}}\right.$, is addressed. As was expected a priori, the $\mathrm{j}=7$ scenario has a much lower index of dissimilarity $(\mathrm{I}=0.143$, where $0 \leq \mathrm{I} \leq 1))$ than the $j=4$ scenario $(I=0.270)$, indicating that the values of $b_{i}$ in equation (18) will closely resemble the benchmark values of $b_{i}$ in equation (4) only when many (few) industries are assigned as nonbasic (basic).

According to the four criteria adopted above, it can be safely concluded that the best strategy when using method 1 economic base analysis is to assign only four industries as nonbasic and to assign the remaining six industries as basic.

When method 2 is adopted per equation (20), the highest adjusted $R^{2}(0.753)$ for the eight assignment scenarios is again found in the $j=4$ case and the lowest $R^{2}$ ( 0.569$)$ is again found in the $j=7$ case. Moreover, it is very evident that transfer payments play a role in the assignment model comparable to their role seen earlier in the benchmark model; for instance, in the $j=4$ case, the adjusted $R^{2}$ rises from 0.448 in equation (16) to 0.753 in equation (20). Now, however, one of the three $\mathrm{j}=5$ cases provides the assignment multiplier estimate $\left(\mathrm{M}_{\gamma}=1.435\right)$ closest to that of the benchmark multiplier estimate $\left(M_{\alpha}=1.440\right)$, although the $j=4$ case provides 
TABLE 2

Estimates on Community-Wide Basic Employment for the Assignment Model:

Methods 1 and 2

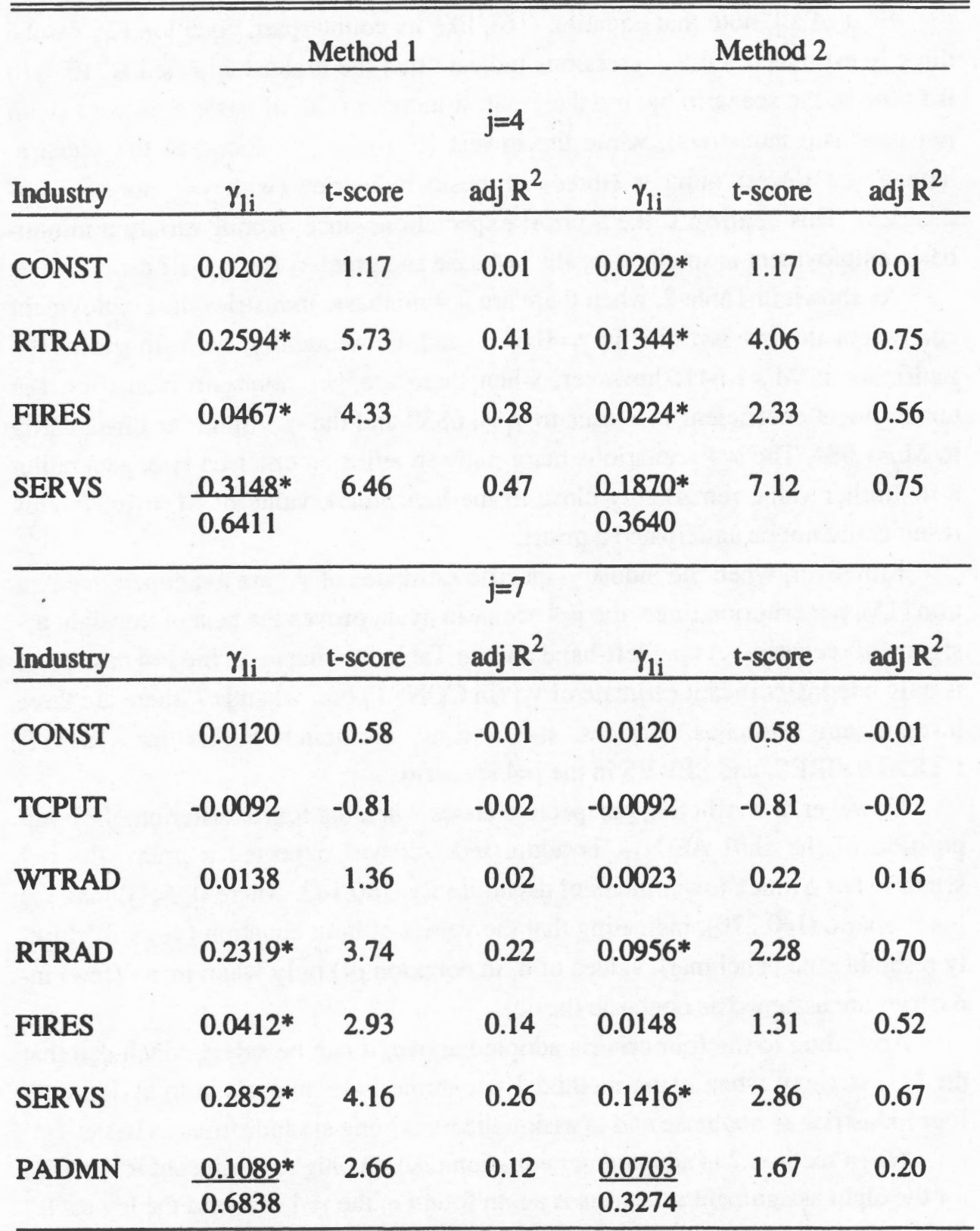

Note: The estimates pertain to the employment coefficients of equations (15) and (19). The variable $\mathrm{j}$ indicates the number of nonbasic sectors used in the estimation. The left-hand data show estimates based on basic employment only, while the right-hand data show estimates based on basic employment and transfer payments. The asterisks indicate those employment estimates significant at the 0.05 level. 
a very satisfactory third-best estimate $\left(M_{\gamma}=1.363\right)$. The right-hand data in Table 2 show the employment estimates $\gamma_{1 \mathrm{i}}$ in both the $\mathrm{j}=4$ and $\mathrm{j}=7$ assignment scenarios. Note, as in method 1 , that the $j=4$ estimates are generally superior to the $j=7$ estimates. Again, as was anticipated a priori, the index of dissimilarity is much higher for the $j=4$ scenario $(I=0.312)$ than for the $j=7(I=0.230)$ scenario. It came somewhat as a surprise that the two indices would be higher than their method 1 counterparts; this result occurs because method 2 inflates the overpredictions of employment in PADMN and SERVS. Overall, though, it can be safely concluded that the $\mathrm{j}=4$ assignment scenario performs best for method 2 economic base analysis.

Recall that methods 3 and 4 use community-wide total employment as an independent variable. Thus, for the assignment approach, total employment $\mathrm{E}(\mathrm{N})_{\mathrm{Ti}}$ in the ith $(1 \leq i \leq j \leq 7)$ nonbasic industry is estimated as a function of (residual) com-

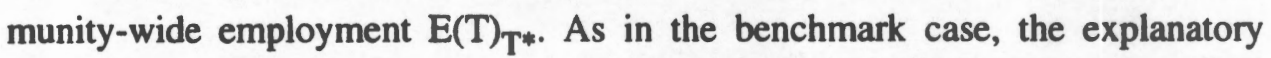
power of the model is not estimated directly (criterion 1). The appropriate assignment counterparts to equations (7) through (14) become:

$$
\begin{aligned}
\mathrm{E}(\mathrm{N})_{\mathrm{Ti}} & =\gamma_{0 \mathrm{i}}+\gamma_{1 \mathrm{i}} \mathrm{E}(\mathrm{T})_{\mathrm{T}^{*}}+\mathrm{e} \\
\mathrm{E}(\mathrm{N})_{\mathrm{Ti}} & =\lambda 0 \mathrm{i}+\lambda_{1 \mathrm{i}} \mathrm{E}(\mathrm{T})_{\mathrm{T}} \\
\mathrm{E}\left(\mathrm{N}_{\mathrm{T}}\right. & =\lambda_{0}+\lambda_{1} \mathrm{E}(\mathrm{T})_{\mathrm{T}} \\
\mathrm{M}_{\lambda} & =1 /\left(1-\lambda_{1}\right) \\
b_{\mathrm{i}} & =\left(\lambda_{1 i} \lambda_{1}\right) \times 100 \% \\
\mathrm{E}(\mathrm{N})_{\mathrm{Ti}} & =\gamma_{0 \mathrm{i}}+\gamma_{1 \mathrm{i}} \mathrm{E}(\mathrm{T})_{\mathrm{T}^{*}}+\gamma_{2 \mathrm{i}} \mathrm{TR}+\mathrm{e} \\
\mathrm{E}(\mathrm{N})_{\mathrm{Ti}} & =\lambda_{0 \mathrm{i}}+\lambda_{1 \mathrm{i}} \mathrm{E}(\mathrm{T})_{\mathrm{T}}+\lambda_{2 \mathrm{i}} \mathrm{TR} \\
\mathrm{E}(\mathrm{N})_{\mathrm{T}} & =\lambda_{0}+\lambda_{1} \mathrm{E}(\mathrm{T})_{\mathrm{T}}+\lambda_{2} \mathrm{TR} .
\end{aligned}
$$

Table 3 shows the employment estimates $\gamma_{1 \mathrm{i}}$ (and the adjusted estimates $\lambda_{1 \mathrm{i}}$ ), based on equations (21) and (22), for all seven possible nonbasic industries. Upon comparing the left-hand data of this table to the left-hand data of Table 2, note that the estimates given by method 3 are clearly superior to those provided by method 1 (per criterion 3). For the $\mathrm{j}=4$ scenario, three of the four employment estimates are significant at the 0.10 level, the employment coefficient in equation (23) is $\lambda_{1}=0.4476$, and the estimate of the multiplier in equation (24) is 
TABLE 3

Estimates on Community-Wide Total Employment for the Assignment Model: Methods 3 and 4

\begin{tabular}{|c|c|c|c|c|c|c|}
\hline \multirow[b]{2}{*}{ Industry } & \multicolumn{3}{|c|}{ Method 3} & \multicolumn{3}{|c|}{ Method 4} \\
\hline & $\gamma_{1 \mathrm{i}}\left(\lambda_{1 \mathrm{i}}\right)$ & t-score & $\operatorname{adj} R^{2}$ & $\gamma_{11}\left(\lambda_{1 j}\right)$ & $\mathrm{t}$-score & $\operatorname{adj} \mathbf{R}^{2}$ \\
\hline CONST & $\begin{array}{c}0.0163 \\
(0.0161)\end{array}$ & 1.69 & 0.04 & $\begin{array}{c}0.0163 \\
(0.0161)\end{array}$ & 1.69 & 0.04 \\
\hline TCPUT & $\begin{array}{c}0.0243 \\
(0.0237)\end{array}$ & 1.30 & 0.01 & $\begin{array}{c}0.0243 \\
(0.0237)\end{array}$ & 1.30 & 0.01 \\
\hline WTRAD & $\begin{array}{c}0.0161 * \\
(0.0158)\end{array}$ & 3.74 & 0.22 & $\begin{array}{c}0.0161 * \\
(0.0158)\end{array}$ & 3.74 & 0.22 \\
\hline RTRAD & $\begin{array}{c}0.2181 * \\
(0.1791)\end{array}$ & 8.68 & 0.62 & $\begin{array}{c}0.1256^{*} \\
(0.1116)\end{array}$ & 5.33 & 0.79 \\
\hline FIRES & $\begin{array}{c}0.0380 * \\
(0.0366)\end{array}$ & 7.78 & 0.56 & $\begin{array}{c}0.0248 * \\
(0.0242)\end{array}$ & 4.08 & 0.64 \\
\hline SERVS & $\begin{array}{c}0.2752 * \\
(0.2158)\end{array}$ & 10.34 & 0.70 & $\begin{array}{c}0.1850 * \\
(0.1561)\end{array}$ & 6.81 & 0.81 \\
\hline PADMN & $\begin{array}{c}0.0825^{*} \\
(0.0762)\end{array}$ & 4.34 & 0.28 & $\begin{array}{c}0.0825^{*} \\
(0.0762)\end{array}$ & 4.34 & 0.28 \\
\hline
\end{tabular}

Totals
$\mathrm{j}=4$
0.4476
0.3080

$\mathrm{j}=7$

Note: The estimates pertain to the employment coefficients of equations (21), (22), (26), and (27). Adjusted estimates, used in computing the total figures at the bottom of the table, are shown in parentheses. The variable $j$ indicates the number of nonbasic industries used in the estimation. The left-hand data show estimates based on total employment only, while the right-hand data show estimates based on total employment and transfer payments. The asterisks indicate those employment estimates significant at the 0.05 level. 
$M_{\lambda}=1.810$; on the other hand, for the $j=7$ scenario, only five of the seven estimates are significant, $\lambda_{1}=0.5633$, and the multiplier estimate is $M_{\lambda}=2.290$. Since the benchmark multiplier estimate is $\mathrm{M}_{\beta}=1.741$, the $\mathrm{j}=4$ scenario clearly outperforms the $j=7$ scenario on criterion two. Since all other assignment scenarios generate multiplier values between these lower and upper bounds, the assignment method always overpredicts method 3 multipliers. Upon examining the values of $b_{i}$ in the two cases, the industry-specific allocation of the impact is found to be most similar to the benchmark case when $j=7(I=0.102)$ and least similar when $j=4(I=0.262)$. Based on the three relevant criteria, however, the $j=4$ assignment scenario is again rated the best for method 3 economic base analysis.

Table 3 also shows the estimates $\gamma_{1 \mathrm{i}}\left(\lambda_{1 \mathrm{i}}\right)$, based on equations (26) and (27), for the same $j=4$ and $j=7$ assignment scenarios. As was disclosed earlier for the benchmark case, the introduction of transfer payments shifts downward the employment coefficients in most industries, particularly in RTRAD and SERVS. Upon comparing the right-hand data of Table 3 to the right-hand data of Table 2, note that the estimates provided by method 4 are clearly superior to those given by method 2 . Also, when there are $j=4$ nonbasic industries, the employment coefficient of equation (28) falls to $\lambda_{1}=0.3080$ while the multiplier estimate declines to $M_{\lambda}=1.445$; however, when there are $j=7$ nonbasic industries, $\lambda_{1}=0.4237$ and $M_{\lambda}=1.735$. Since the benchmark multiplier estimate is $M_{\beta}=1.478$ the $j=4$ assignment scenario clearly outperforms the $j=7$ scenario. As to the distribution of $b_{i}$, the impact allocation is again most similar to the benchmark case when $j=7$ $(I=0.139)$ and least similar when $j=4(I=0.341)$. It is worth noting that the values for the index of dissimilarity were found to be higher for method 4 than for method 2, a surprising result. Clearly, though, the $j=4$ assignment scenario is again superior to the $\mathrm{j}=7$ scenario for method 4 economic base analysis.

\section{CLASSIFICATION AND DUMMY VARIABLES}

Mulligan and Fik (1994) have recently used dummy variables with OLS regression to estimate community-wide nonbasic employment, thereby generating different economic base multipliers for different types of communities. By using dummy variables they were able to avoid some of the small-sample concerns that plagued the earlier study by Mulligan and Kim (1991).

This paper uses the same classification scheme found in Mulligan and Fik but employs only five community-specific categories: $D_{1}$, diversified; $D_{2}$, manufacturing; $D_{3}$, mining; $D_{4}$, service and trade; and $D_{5}$, utility. These five categories account for 38 of the 47 observations in the ACDS. As is the usual case with dummy-variable classifications, a community of the kth type is assigned the 
value $D_{k}=1$, while a community not of the kth type is assigned the value $D_{k}=0$. Interaction effects between dummy variables were not considered because all community classifications are mutually exclusive.

The variable $D_{k}$ was considered with the intercept term, the community-wide employment variable, and (when appropriate) the transfer-payment variable. Estimation procedures were based on stepwise regression using equations (1), (5), (7), and (12) for the benchmark model and equations (15), (19), (21), and (26) for the assignment model. The analysis was confined only to the $j=4$ assignment scenario because it outperformed other scenarios prior to the classification of communities. The estimates were selected only if they met entry requirements identical to those stated earlier in the paper. Tolerance tests were used to ensure that collinearity of the independent variables did not present a problem.

Table 4 shows the employment estimates for the benchmark (top half) and $\mathrm{j}=4$ assignment (bottom half) economic base models, indicating first the results for method 1 (top line) and then those for method 2 (bottom line). Returning to Tables 1 and 2 , note first that the adjusted $R^{2}$ is shifted upward for the various employment sectors, especially in those industries (e.g., MINIG, CONST) that had poor estimates when classification procedures were not used. Also, note that, even with classification, transfer payments still play an important role in generating nonbasic employment in most industries: in the benchmark model the method 2 estimates are different from those of method 1 in six of the nine cases, while in the assignment model the method 2 estimates are different in three of the four cases. It is also encouraging that methods 1 and 2 generally retain the same dummy variables throughout the various pairs of regression runs. To avoid cluttering the table, estimates for the intercepts and transfer-payment coefficients are not shown. ${ }^{4}$

Table 5 repeats the exercise for methods 3 and 4 . In general, the adjusted $R^{2}$ is now higher than in the counterpart case of method 1 or 2 , but this finding is not universally true. It is also interesting to note that the results of Tables 4 and 5 are highly correlated; that is, those industries that have good (bad) estimates with methods 1 and 2 tend to have good (bad) estimates with methods 3 and 4.

Finally, Table 6 summarizes the results of these last estimation procedures for the five different types of community specialization. For each of the four methods the estimate $M_{B}$ of the benchmark model and the estimate $M_{A}$ of the $j=4$ assignment model are given, and the percentage error of the latter approach is noted. In all but the service and trade communities the assignment model gives a very adequate estimate of the economic base multiplier, generating a marginally lower multiplier in diversified towns and a marginally higher estimate in the other three types of communities. The discrepancy in the multipliers of service and trade communities $\left(D_{4}\right)$ reflects the fact that community-wide employment 
TABLE 4

Benchmark and Assignment Employment Estimates with Dummy Variables: Methods 1 and 2

\begin{tabular}{|c|c|c|c|c|c|c|c|}
\hline & $\mathrm{E}_{B}$ & $\mathrm{D}_{1}$ & $D_{2}$ & $D_{3}$ & $\mathrm{D}_{4}$ & $\mathrm{D}_{5}$ & $\operatorname{Adj} R^{2}$ \\
\hline AGRIC & - & $\begin{array}{l}0.0138 \\
0.0104\end{array}$ & & & $\begin{array}{l}0.0122 \\
0.0094\end{array}$ & & $\begin{array}{l}0.25 \\
0.33\end{array}$ \\
\hline MINIG & - & $\begin{array}{l}0.0178 \\
0.0178\end{array}$ & & $\begin{array}{l}0.0026 \\
0.0026\end{array}$ & & & $\begin{array}{l}0.60 \\
0.60\end{array}$ \\
\hline CONST & $\begin{array}{l}0.0386 \\
0.0189\end{array}$ & 0.0189 & $\begin{array}{l}0.0397 \\
0.0591\end{array}$ & -0.0210 & & & $\begin{array}{l}0.46 \\
0.50\end{array}$ \\
\hline MANUF & $\begin{array}{l}0.0528 \\
0.0528\end{array}$ & & & $\begin{array}{l}-0.0384 \\
-0.0384\end{array}$ & $\begin{array}{l}-0.0304 \\
-0.0304\end{array}$ & & $\begin{array}{l}0.60 \\
0.60\end{array}$ \\
\hline TCPUT & $\begin{array}{l}0.0400 \\
0.0400\end{array}$ & & & & & & $\begin{array}{l}0.10 \\
0.10\end{array}$ \\
\hline WTRAD & $\begin{array}{l}0.0100 \\
0.0115\end{array}$ & & $\begin{array}{l}0.0109 \\
0.0112\end{array}$ & & 0.0150 & & $\begin{array}{l}0.35 \\
0.47\end{array}$ \\
\hline RTRAD & $\begin{array}{l}0.1964 \\
0.1069\end{array}$ & & & & & & $\begin{array}{l}0.50 \\
0.79\end{array}$ \\
\hline FIRES & $\begin{array}{l}0.0544 \\
0.0320\end{array}$ & & 0.0113 & $\begin{array}{l}-0.0197 \\
-0.0112\end{array}$ & & & $\begin{array}{l}0.60 \\
0.82\end{array}$ \\
\hline SERVS & $\begin{array}{l}0.1939 \\
0.1056\end{array}$ & & $\begin{array}{l}0.0796 \\
0.0743\end{array}$ & & & 0.1041 & $\begin{array}{l}0.56 \\
0.83\end{array}$ \\
\hline PADMN & $\begin{array}{l}0.0697 \\
0.0719\end{array}$ & & & -0.0222 & & & $\begin{array}{l}0.57 \\
0.68\end{array}$ \\
\hline & $\mathrm{E}(\mathrm{B}) \mathrm{T}$ & $\mathrm{D}_{1}$ & $D_{2}$ & $D_{3}$ & $\mathrm{D}_{4}$ & D5 & Adj $\mathbf{R}^{2}$ \\
\hline CONST & - & & $\begin{array}{l}0.1883 \\
0.1883\end{array}$ & $\begin{array}{l}0.0771 \\
0.0771\end{array}$ & $\begin{array}{l}0.0640 \\
0.0640\end{array}$ & & $\begin{array}{l}0.20 \\
0.20\end{array}$ \\
\hline RTRAD & $\begin{array}{l}0.2647 \\
0.1563\end{array}$ & & & & $\begin{array}{l}0.4208 \\
0.2779\end{array}$ & & $\begin{array}{l}0.41 \\
0.83\end{array}$ \\
\hline FIRES & $\begin{array}{l}0.0739 \\
0.0512\end{array}$ & & & $\begin{array}{l}-0.0385 \\
-0.0306\end{array}$ & $\begin{array}{l}0.0917 \\
0.0714\end{array}$ & & $\begin{array}{l}0.61 \\
0.74\end{array}$ \\
\hline SERVS & $\begin{array}{l}0.2953 \\
0.1634\end{array}$ & & $\begin{array}{l}0.1833 \\
0.1390\end{array}$ & & $\begin{array}{l}0.4816 \\
0.5671\end{array}$ & 0.2107 & $\begin{array}{l}0.67 \\
0.87\end{array}$ \\
\hline
\end{tabular}

Note: The top half of the table refers to the benchmark model, while the bottom half refers to the $j=4$ assignment model. In each case the estimates on the upper line refer to method 1 and those on the lower line to method 2. Method 2 estimates for transfer payments are not shown. All employment estimates are significant at the 0.10 level. 
TABLE 5

Benchmark and Assignment Employment Estimates with Dummy Variables: Methods 3 and 4

\begin{tabular}{|c|c|c|c|c|c|c|c|}
\hline & $\mathrm{E}_{\mathrm{B}}$ & $\mathrm{D}_{1}$ & $\mathrm{D}_{2}$ & $\mathrm{D}_{3}$ & $\mathrm{D}_{4}$ & Ds & $\operatorname{Adj} R^{2}$ \\
\hline AGRIC & 0.0089 & 0.0143 & & -0.0067 & 0.0059 & & $\begin{array}{l}0.35 \\
0.44\end{array}$ \\
\hline MINIG & - & $\begin{array}{l}0.0093 \\
0.0145\end{array}$ & & $\begin{array}{l}0.0018 \\
0.0018\end{array}$ & & & $\begin{array}{l}0.60 \\
0.80\end{array}$ \\
\hline CONST & $\begin{array}{l}0.0240 \\
0.0240\end{array}$ & & $\begin{array}{l}0.0235 \\
0.0235\end{array}$ & $\begin{array}{l}-0.0114 \\
-0.0114\end{array}$ & & & $\begin{array}{l}0.56 \\
0.56\end{array}$ \\
\hline MANUF & $\begin{array}{l}0.0310 \\
0.0310\end{array}$ & & & $\begin{array}{l}-0.0213 \\
-0.0213\end{array}$ & $\begin{array}{l}-0.0178 \\
-0.0178\end{array}$ & & $\begin{array}{l}0.67 \\
0.67\end{array}$ \\
\hline TCPUT & $\begin{array}{l}0.0258 \\
0.0258\end{array}$ & & & & & & $\begin{array}{l}0.13 \\
0.13\end{array}$ \\
\hline WTRAD & $\begin{array}{l}0.0076 \\
0.0081\end{array}$ & & $\begin{array}{l}0.0055 \\
0.0052\end{array}$ & & 0.0097 & & $\begin{array}{l}0.51 \\
0.55\end{array}$ \\
\hline RTRAD & $\begin{array}{l}0.1500 \\
0.1008\end{array}$ & & & & 0.0378 & & $\begin{array}{l}0.70 \\
0.85\end{array}$ \\
\hline FIRES & $\begin{array}{l}0.0351 \\
0.0240\end{array}$ & & 0.0057 & $\begin{array}{l}-0.0109 \\
-0.0066\end{array}$ & & & $\begin{array}{l}0.80 \\
0.87\end{array}$ \\
\hline SERVS & $\begin{array}{l}0.1492 \\
0.0871\end{array}$ & & $\begin{array}{l}0.0438 \\
0.0474\end{array}$ & & & 0.0788 & $\begin{array}{l}0.71 \\
0.85\end{array}$ \\
\hline PADMN & $\begin{array}{l}0.0504 \\
0.0504\end{array}$ & & $\begin{array}{l}-0.0165 \\
-0.0165\end{array}$ & & & & $\begin{array}{l}0.73 \\
0.73\end{array}$ \\
\hline & $\mathrm{E}(\mathrm{B}) \mathrm{T}$ & $\mathrm{D}_{1}$ & $\mathrm{D}_{2}$ & $\mathrm{D}_{3}$ & $\mathrm{D}_{4}$ & Ds & $\operatorname{Adj~} R^{2}$ \\
\hline CONST & - & . & $\begin{array}{l}0.0363 \\
0.0363\end{array}$ & & & $\begin{array}{l}0.0802 \\
0.0802\end{array}$ & $\begin{array}{l}0.17 \\
0.17\end{array}$ \\
\hline RTRAD & $\begin{array}{l}0.2076 \\
0.1298\end{array}$ & & & & $\begin{array}{l}0.1387 \\
0.1014\end{array}$ & & $\begin{array}{l}0.72 \\
0.84\end{array}$ \\
\hline FIRES & $\begin{array}{l}0.0453 \\
0.0363\end{array}$ & & & $\begin{array}{l}-0.0183 \\
-0.0163\end{array}$ & $\begin{array}{l}0.0198 \\
0.0179\end{array}$ & & $\begin{array}{l}0.76 \\
0.78\end{array}$ \\
\hline SERVS & $\begin{array}{l}0.2474 \\
0.1778\end{array}$ & & $\begin{array}{l}0.0897 \\
0.0804\end{array}$ & & $\begin{array}{l}0.1606 \\
0.1222\end{array}$ & & $\begin{array}{l}0.79 \\
0.86\end{array}$ \\
\hline
\end{tabular}

Note: The top half of the table refers to the benchmark model, while the bottom half refers to the $j=4$ assignment model. In each case the estimates on the upper line refer to method 3 and those on the lower line to method 4 . All estimates are in unadjusted form. Method 4 estimates for transfer payments are not shown. All employmentestimates are significant at the 0.10 level. 
TABLE 6

Summary of Dummy Variable Analysis for All Four Assignment Methods; $j=4$ Nonbasic Industries

\begin{tabular}{lcccccc}
\hline & Diversified & Manufacturing & Mining & $\begin{array}{c}\text { Service \& } \\
\text { Trade }\end{array}$ & Utility & All \\
\hline \multicolumn{7}{c}{ Method 1 } \\
\hline & & & & & \\
MB & 1.687 & 1.786 & 1.579 & 1.652 & 1.655 & 1.637 \\
MA & 1.634 & 1.895 & 1.595 & 2.692 & 1.822 & 1.641 \\
\% error & -3.14 & 6.10 & 1.01 & 62.95 & 10.09 & 0.24 \\
I & 0.353 & 0.247 & 0.266 & 0.281 & 0.263 & 0.270
\end{tabular}

Method 2

$\begin{array}{lllllll}\mathrm{MB}_{\text {B }} & 1.487 & 1.573 & 1.393 & 1.422 & 1.543 & 1.441 \\ \mathrm{M}_{\mathrm{A}} & 1.371 & 1.698 & 1.417 & 2.351 & 1.582 & 1.363 \\ \text { \% error } & -7.80 & 7.95 & 1.72 & 65.33 & 2.53 & -5.41 \\ \mathrm{I} & 0.499 & 0.313 & 0.361 & 0.373 & 0.458 & 0.312\end{array}$

Method 3

$\begin{array}{lllllll}\mathrm{M}_{\mathrm{B}} & 1.807 & 1.929 & 1.642 & 1.844 & 1.778 & 1.741 \\ \mathrm{M}_{\mathrm{A}} & 1.706 & 2.010 & 1.657 & 2.553 & 1.953 & 1.810 \\ \text { \% error } & -5.58 & 4.20 & 0.91 & 38.45 & 9.84 & 3.96 \\ \mathrm{I} & 0.296 & 0.291 & 0.341 & 0.251 & 0.273 & 0.262\end{array}$

Method 4

\begin{tabular}{lclllll}
$\mathrm{M}_{B}$ & 1.558 & 1.627 & 1.416 & 1.468 & 1.645 & 1.478 \\
$\mathrm{M}_{\mathrm{A}}$ & 1.430 & 1.640 & 1.399 & 1.886 & 1.600 & 1.445 \\
\% error & -8.21 & 0.80 & 1.20 & 28.47 & 2.43 & -2.23 \\
$\mathrm{I}$ & 0.461 & 0.290 & 0.357 & 0.387 & 0.226 & 0.341 \\
\hline
\end{tabular}

Note: $\mathrm{M}_{\mathrm{B}}$ is the estimate of the benchmark multiplier, $\mathrm{M}_{\mathrm{A}}$ is the estimate of the assignment multiplier, \% error is the percentage error in the assignment multiplier, and $I$ is the index of dissimilarity for the two multiplier-induced percentage shifts in nonbasic employment. 
generates large amounts of nonbasic employment in RTRAD, FIRES, and SERVS according to the assignment model, but does not generate any nonbasic employment in these three sectors according to the benchmark model. Table 6 also shows the dissimilarity index I, highlighting the differences in the composition of the multiplier effect, for the various cases. For completeness, the table shows the results reported earlier in the paper for all 47 communities in the ACDS.

\section{CONCLUDING REMARKS}

This paper has evaluated the assignment or assumption method of economic base analysis, where entire industries are designated as being either basic or nonbasic. Using the ten industries of the Arizona Community Data Set, various assignment scenarios were evaluated. OLS regression was used to estimate industry-level nonbasic employment in both the "incorrect" assignment model and the "correct" benchmark model, and then the resulting multiplier estimates were compared. Four competing versions of economic base analysis were examined in detail.

The paper disclosed that an assignment model using $\mathrm{j}=4$ nonbasic industries (CONST, RTRAD, FIRES, and SERVS) provided remarkably accurate estimates of the benchmark multiplier when all communities in the ACDS were used. This finding held across the various versions of economic base analysis. In one case (method 1) the assignment estimate of the multiplier was within one percent of the benchmark estimate; in two cases (methods 3 and 4 ) the assignment estimate was within four percent of the benchmark estimate; and in only one case (method 2) was the assignment estimate of the multiplier more than five percent different from the benchmark estimate. When transfer payments were excluded (included) from the estimation, the assignment multiplier slightly overpredicted (underpredicted) the benchmark multiplier. Subsequent stepwise regression analysis, using dummy variables, focused on indentifying different multiplier estimates for different types of community specializations. Using $j=4$ nonbasic industries, entirely satisfactory multiplier estimates were given by the assignment method for diversified, manufacturing, mining, and utility centers; however, multiplier estimates for service and trade towns were severely overpredicted by the assignment method.

The final conclusions of the paper are somewhat mixed. Practitioners who have adopted the assignment method, either in cross-sectional or longitudinal studies, have probably erred very little in their estimates of the sizes of regional multipliers. Further study of the issue is warranted, though, since it is unclear how 
representative the ACDS is of all U.S. communities, or, for that matter, how the results for small communities would carry into larger regions. On the other hand, it is very clear that these assignment-based studies, invariably performed at high levels of industrial aggregation, have not provided accurate information about the composition of regional employment (income) impacts.

\section{ENDNOTES}

1. Gibson and Worden (1981) critiqued other shortcut methods (location quotient, minimum requirements), but not the assignment method, when they examined a portion of the Arizona Community Data Set. Their analysis, however, was confined to community-specific average multipliers and did not address either sample-wide or type-specific marginal multipliers.

2. The data base is available from the authors upon request.

3. Values for $b_{i}$ are given in Mulligan and Vias (1996). Here the industrylevel estimates of nonbasic employment are provided for all of the benchmark and assignment cases discussed in the paper.

4. These estimates are available upon request from the authors.

\section{REFERENCES}

Armstrong, Harvey, and Jim Taylor. Regional Economics and Policy. (2nd edition). 1993. (Hemel Hempstead, U.K.: Harvester Wheatsheaf).

Braschler, Curtis. "A Comparison of Least-Squares Estimates of Regional Employment Multipliers with Other Methods." Journal of Regional Science 12 (1972): 457-468.

Chalmers, James A., and Eric J. Anderson. Economic/Demographic Manual. 1977. Tempe: Mountain West Research.

Chalmers, James A., Eric J. Anderson, Terrance Beckhelm, and William Hannigan. "Spatial Interaction in Sparsely Populated Areas: An Hierarchical Economic Base Approach." International Regional Science Review 3 (1978): 75-92.

Garnick, Daniel. "Differential Regional Multiplier Models." Journal of Regional Science 10 (1970): 35-47.

Gibson, Lay J., and Marshall A. Worden. "Estimating the Economic Base Multiplier: A Test of Alternative Procedures." Economic Geography 457 (1981): 146-159. 
Hewings, Geoffrey J. D. Regional Industrial Analysis and Development. 1977. (New York: St. Martin's Press).

Isserman, Andrew M. "Estimating Export Activity in a Regional Economy: A Theoretical and Empirical Analysis of Alternative Methods." International Regional Science Review 5 (1980): 155-184.

Malecki, Edward J. Technology and Economic Development: The Dynamics of Local, Regional and National Change. (New York: John Wiley and Sons).

McNulty, James E. "A Test of the Time Dimension in Economic Base Analysis." Land Economics 53 (1977): 359-368.

Moody, Harold T., and Frank W. Puffer. "The Empirical Verification of the Urban Base Multiplier: Traditional and Adjustment Process Models." Land Economics 46 (1970): 91-98.

Mulligan, Gordon F., and Timothy J. Fik. "Using Dummy Variables to Estimate Economic Base Multipliers." Professional Geographer 46 (1994): 368-378.

Mulligan, Gordon F., and Lay J. Gibson. "Regression Estimates of Economic Base Multipliers for Small Communities." Economic Geography 60 (1984): 225-237.

Mulligan, Gordon F., and Hak-Hoon Kim. "Sectoral-Level Employment Multipliers in Small Urban Settlements: A Comparison of Five Models." Urban Geography 12 (1991): 240-259.

Mulligan, Gordon F., and Alexander C. Vias. Estimating the Economic Base Multiplier: An Assessment of the Assignment Method. Discussion Paper 96-1, Department of Geography and Regional Development, University of Arizona, 1996.

Polzin, Paul. "Urban Employment Models: Estimation and Interpretation." Land Economics 49 (1973): 226-232.

Polzin, Paul. "Urban Labor. Markets: A Two-Sector Approach." Growth and Change 8 (1977): 11-15.

Richardson, Harry W. "Input-Output and Economic Base Multipliers: Looking Backward and Forward." Journal of Regional Science 25 (1985): 607-661.

Weiss, Steven J., and Edwin C. Gooding. "Estimation of Differential Employment Multipliers in a Small Regional Economy." Land Economics 44 (1968): 235244. 